\title{
The Case for an Autonomy-Centered View of Physician-Assisted Death
}

\author{
Dr. Jeremy Davis \\ United States Military Academy \\ Dr. Eric Mathison \\ Alberta Health Services
}

(forthcoming in the Journal of Bioethical Inquiry; please cite published version)

\begin{abstract}
Most people who defend physician-assisted death (PAD) endorse the Joint View, which holds that two conditions - autonomy and welfare - must be satisfied for PAD to be justified. In this paper, we defend an Autonomy Only view. We argue that the welfare condition is either otiose on the most plausible account of the autonomy condition, or else is implausibly restrictive, particularly once we account for the broad range of reasons patients cite for desiring PAD, such as "tired of life" cases. Moreover, many of the common objections to an Autonomy Only view fail once we understand the extent of the autonomy condition's requirements - in particular, the importance of one's values for autonomous choices. If our view is correct, then the scope of permissible PAD is broader than is currently accepted in both the philosophical literature and the law, and therefore poses an important challenge to this widely accepted view on justified PAD.
\end{abstract}

\section{Introduction}

The view that physician-assisted death $(\mathrm{PAD})$ is permitted under certain conditions receives wide support in both the philosophical literature and, increasingly, among the public in general, at least in many Western countries. Despite this growing consensus, there is still considerable disagreement concerning which conditions must be satisfied for PAD to be permissible. The most popular view in the philosophical literature on PAD is known as the Joint View (De Haan 2002; Sumner 2011; Sumner 2017). This view holds that PAD is permissible only when two conditions are satisfied-namely, autonomy and welfare. Much of the current philosophical disagreement 
concerning PAD centers on how best to understand these two conditions; but it is generally thought that some form of both of these conditions must be satisfied for PAD to be permissible.

In this paper, we challenge this approach by articulating the ethical foundations of the view that autonomy, properly understood, is the only necessary condition for permissible PAD. We argue that an Autonomy Only view is plausible, and boasts certain advantages that the Joint View lacks. On the Autonomy Only view, an autonomous request for PAD is sufficient for its moral permissibility. Moreover, we argue that, once we have in place a reasonable view of what the autonomy condition requires, many of the familiar or intuitively plausible objections to an Autonomy Only view fail. At a minimum, then, philosophers ought to take this view more seriously. And if Autonomy Only is indeed correct, then the scope of moral permissibility for PAD is much broader than what is commonly argued in the philosophical literature and what is legally permitted in most places. Here we focus on the ethical justifications for the view, not the practical implications - in terms of the law, policy, and otherwise — of enacting such a view in any particular jurisdiction.

To clarify, our focus in this essay is the debate surrounding the sub-categories of euthanasia typically called either "voluntary physician-assisted suicide" or "voluntary physician-administered euthanasia." The former occurs when a patient self-administers the lethal drug, while the latter occurs when the patient requests that the physician administers the drug. The former is what is required under current Oregon state law, while the latter is possible under current Netherlands and Canadian law (Steinbrook 2008; Sumner 2017, 81-85). These two categories are to be distinguished from other forms of euthanasia, such as non-voluntary euthanasia (e.g., when a physician hastens the death of, say, an infant) or various forms of passive euthanasia (e.g., removing feeding tubes).

\section{Against the Joint View}

Let us begin by looking more closely at the Joint View. Our aim here is to clarify the view's central commitments, as well as certain alternatives that some might endorse. At its core, the Joint View holds that two conditions, autonomy and welfare, are both necessary for permissible PAD. There are usually other necessary conditions as well, particularly in the legal manifestations of this view (Sumner 2011, 171). Given that our focus here is primarily on the philosophical view, we will 
focus on the joint necessity of these conditions - that is, on the question of whether both are indeed necessary.

Our focus in what follows will be primarily on the version of this view defended by L.W. Sumner, as his is the clearest and most explicit. He writes that "The arguments from well-being and autonomy provide the basic justificatory framework for assisted suicide and voluntary euthanasia" (Sumner 2011, 91). Emphasizing the importance of the welfare condition, Jurriaan De Haan writes that, "while the patient's autonomous request for euthanasia is a contributing factor indeed, his condition is an enabling/disabling factor. Despite the patient's autonomous request, euthanasia is only permissible if the patient's suffering is unbearable and hopeless" (De Haan 2002, 169). In addition to its philosophical support, the joint view is also a common framework for jurisdictions where PAD is legal, including Canada, California, Oregon, Vermont, and Washington State - though as we will discuss later, in the case of U.S. states, there is no explicit appeal to suffering (Steinbrook 2008; Sumner 2017, 81-85).

Consider first the autonomy condition. To defend a complete account of autonomy would be too much to undertake here. It will suffice to note the central ideas on which most who employ the notion of autonomy in the context of PAD tend to agree (Huxtable and Moller 2007; Sumner 2011; Sumner 2017). At its core, autonomy involves self-governance or self-determination in accordance with one's self-conception and values. Patients whose decision-making capacities are irretrievably lost (e.g., because of severe dementia or other debilitating illnesses) are therefore incapable of making an autonomous choice concerning PAD; those with severely diminished or inconsistent decision-making capacities will only have corresponding flickers of autonomy (which will no doubt challenge the ability of outsiders to judge whether a choice is autonomous).

Moreover, some (apparent) choices are the result of undue coercion or pressure by outside agents, such as physicians and relatives; by unjust institutions, such as those that unjustly limit access to certain individuals; and by social attitudes or practices that unduly influence an individual's ability to choose (Mackenzie and Stoljar 2000, 4). While most accounts of autonomy (particularly accounts of relational autonomy, which we discuss below) tolerate some measure of outside influence, there are limits: past a certain point, influence can become undue, which turns it into coercion, and the decision is no longer autonomous (Beauchamp and Childress 2012, chapter 4). Extreme hypotheticals make this point most clearly: one's decision is surely not autonomous when it is the product of another's threat to kill his family. The important point to 
note here, however, is that not all influence is undue or coercive, and not all autonomous choices have to be self-regarding or self-interested. The decisions we make affect others, and we often make our most important decisions with consideration toward its effects on those we care about most.

Another essential component for autonomy is that decisions must be reasonably informed (Beauchamp and Childress 2012, chapter 4). In the present context, this means that physicians have a duty to inform patients of the full range of facts relevant to them, including the possible risks and effects of the selected procedure, all relevant alternative courses of treatment or action, and so forth. A decision made in the absence of these facts fails to satisfy autonomy. ${ }^{1}$

Autonomy is also context-relative (Buchanan and Brock 1990). Roughly put, the threshold for a decision to count as autonomous is relative to the circumstances: low-stakes decisions require only a relatively low level of decisional capacity, whereas high-stakes decisions require a relatively high level of capacity. Of course, this is true in all medical contexts: deciding whether or not to get a wound bandaged requires a rather low level of capacity, while deciding whether or not to decline or cease life-saving treatment requires a rather high level of capacity. The idea as it applies to PAD, then, is just an extension of this more basic point.

We have thus far focused on an individualistic conception of autonomy. But it is also worth noting that individuals are embedded in social networks, and are subject to a range of social conditions and forces, all of which affect how we (and they) understand their autonomy (Mackenzie and Stoljar 2000). So, in addition to this individualistic approach to autonomy, a full theory of autonomy in this context must also account for its relational aspects (Jennings 2016). While much could be said about relational autonomy in this context, we will restrict ourselves to a few points. First, our best understanding of autonomy must be informed by the myriad ways these various relations and forces affect an individual's conception of self, environment, and choice. These relations and forces can manifest as limits to autonomy, in the form of oppression and coercion (McLeod and Sherwin 2000). But we need not view all such relations in this way. Indeed, many of these relations are essential to a complete understanding of the self, and play an important and welcome role in one's decision-making (Ho 2008). Relational autonomy has

\footnotetext{
${ }^{1}$ Of course, this is just another way of describing the right of informed consent, which is most-often grounded in autonomy, but can also be grounded in welfare. There is perhaps a worry here about cases in which patients autonomously forgo this knowledge. This is an important question, but it is beyond the scope of this discussion.
} 
particular salience in the context of PAD, where relationships of care are at the forefront, and members of particularly vulnerable groups are subject to a range of harms and costs (Downie and Sherwin 19996; Donchin 2000).

To motivate our view, it is not necessary to enter the considerable debate about the nature of autonomy and the conditions under which it applies or is defeated in a medical context. In what follows, our argument should be taken to be neutral between the various conceptions of autonomy.

We agree with defenders of the Joint View that the autonomy condition is essential for PAD to be justified. We part company with them, however, on the second part of the Joint Viewnamely, the welfare condition. According to this condition, there is a threshold for welfare-i.e., the amount of intrinsic goods that make one well off or one's life go well — such that, if one's welfare falls below the threshold, it is pro tanto permissible to end that person's life because it lacks sufficient value. Falling below the threshold is possible either by lacking sufficient intrinsic goods or possessing too much intrinsic prudential badness. To endorse the welfare condition for PAD is to accept that some lives can be not worth living. In other words, one's welfare can be such that the amount of badness outweighs the goodness, such that one would be better off dead. In theory, there is considerable disagreement regarding what the constitutive goods and bads are (for a survey of theories of well-being, see Fletcher 2016; for an overview of ill-being, see Kagan 2014). However, in practice, the idea that someone can be sufficiently badly off to justify receiving assistance dying is intuitive. Illness can cause crippling suffering and make valuable activities impossible. In such cases, compassion can require assisting someone in ending such a life (Sumner 2011, 167).

To better understand the welfare condition in the context of PAD, consider the many welfare-based requirements in the jurisdictions in which PAD is currently legal. The Dutch and Canadian policies appeal directly to suffering. The Oregon model, by contrast, requires a terminal illness instead of suffering. For Sumner, who defends a regime similar to what is now law in Canada, the welfare condition is understood as comprising three distinct claims. First, the patient must be suffering intolerably. Second, the patient's suffering must stem from a particular sort of medical condition. And third, no other treatment option for the condition is acceptable to the 
patient. We will use Sumner's description as our standard, since it offers the most detailed requirement for suffering of the three. ${ }^{2}$

Taken on its own, the suffering condition sets quite a low threshold: it is satisfied whenever the patient reports that her condition is intolerable to her. On Sumner's view,

a patient must be afflicted by a kind and degree of suffering that surpasses her limits of toleration. Where those limits lie must be ultimately up to the patient to determine; this will be a personal and individual decision. The suffering in question may, but need not, result from such physical symptoms as pain, nausea, dizziness, shortness of breath, etc. It may also be psychosocial, including such familiar forms of distress as loss of dignity, loss of independence, loss of the ability to do what makes life worth living, etc. (Sumner 2011, 171).

On this view, the suffering condition is fundamentally subjective: whether or not it is satisfied turns on the patient's judgments of what she finds tolerable. Moreover, the suffering condition is silent on the cause of the suffering. Sumner suggests some possible causes in the above passage, though these are best seen as illustrations rather than restrictions. As we will see shortly, Sumner goes on to argue that the suffering must be a result of a medical condition; but this is a distinct criterion. On its own, the suffering condition does not impose any such restrictions. It is simply a question of what the patient finds tolerable: if she finds her condition intolerable, then she is suffering in the sense relevant here.

Our view is that the best interpretation of the suffering condition collapses into the autonomy condition. First, notice that while physical pain is sometimes the reason for requesting $\mathrm{PAD}$, due to many advancements in palliative care - though admittedly lacking in some places, posing a potential challenge to justifying PAD (Barutta and Vollmann 2015) —other forms of suffering of the sort Sumner mentions above are more common (Marquet, et al. 2003; Ganzini 2004; Pearlman and Starks 2004). These are typically due to losing what one once valued-e.g.,

\footnotetext{
2 That welfare and autonomy are treated as separate values in bioethics is at odds with the way many philosophers discuss well-being, which often includes some type of autonomy condition. For examples, see Mill 1859/1975, Kymlicka 1989, and Wall 1998. Sumner's own theory of welfare includes autonomy (Sumner 1996). Because of this, someone might object to our approach by claiming that we can't avoid welfare. By treating autonomy and welfare separately, we are not ruling out this account of welfare, and these accounts are not at odds with our argument, given that they give significant weight to autonomy.
} 
dignity, life projects, independence (Li, et al. 2017, 2082-2088). Many people also suffer from what some have called "life fatigue" (Miller 2016, Huxtable and Moller 2007). Others cite ongoing and incurable psychological distress (Aviv 2015). In some cases, these values might not be entirely agent-centered. For example, one might care deeply about being able to support her family, and the loss of that ability — or worse, becoming a burden — will cause her great suffering. (Note that desires like these are not in tension with our view of autonomy, especially once we account for relational autonomy.)

Such judgments may also focus on expected future suffering. In a recent Canadian case, a 94-year-old man was approved for PAD citing only the combination of age-related frailty and the desire to die alongside his wife of nearly 73 years (Grant 2018). The desire to die with his wife was partly informed by his desire not to endure the suffering in her absence. Or consider the case of Brittany Maynard, a 29-year-old who had terminal brain cancer. As she put it:

[E]ven with palliative medication, I could develop potentially morphine-resistant pain and suffer personality changes and verbal, cognitive and motor loss of virtually any kind. Because the rest of my body is young and healthy, I am likely to physically hang on for a long time even though cancer is eating my mind. I probably would have suffered in hospice care for weeks or even months (Maynard 2014).

The fact that these two cases are non-standard should not deter us from judging that they qualify as suffering, at least in the sense most relevant to PAD.

As we have already seen, what is morally relevant about suffering is that one judges continued life to be intolerable to her. But the foregoing examples show that there are many other ways that life might be intolerable that do not involve pain in the ordinary sense, such as living a life that is inconsistent with one's values, or is otherwise judged to be no longer worth living. Importantly, judging that one's life is not worth living is not restricted to a prudential judgement. People care about living in accordance with their values, and the inability to do so is a significant source of distress. This is so even if one lacks physical suffering. On our view, it is possible to be prudentially well off while judging that something one values that requires death outweighs the prudential value of continued life. To give a non-PAD example, a soldier might judge that he values the other soldiers in his unit more than his own life, should a grenade fall among them. He 
is permitted to make this judgement. Similarly, if a mother decides that she would rather her daughter have her heart, whose own is failing, this is an autonomous judgement that she is justified in making. If suffering is bad, we have reason to ameliorate or prevent it whenever it is or would be intolerable for the subject. If death is the only means the subject finds acceptable, we have reason to grant that (autonomous) request.

But when the suffering condition for PAD is interpreted in this way, it collapses into the autonomy condition. Autonomy, as we have seen, concerns sufficiently well-informed selfgovernance or self-determination in accordance with one's self-conception and values. This is precisely what is at stake in making a judgment about how to end one's life: for some, to go on living a life that is inconsistent with one's values, in any of the aforementioned ways, would constitute a life of intolerable suffering. Given its content, any request for PAD that satisfies autonomy must also include the patient's judgment that her life is no longer worth living for her.

In short, if the subjective assessment that one's suffering is intolerable justifies PAD, then this must include the full range of ways people might face conditions that are intolerable to them, not only the physical kinds of suffering on which many writers have focused. But once the condition is understood this way, as we have argued it must be, then the welfare condition does not require anything beyond what the autonomy condition already stipulates. Suffering is just one instance of the broader category of judging one's life as no longer worth living, which the autonomy condition already captures.

Thus, as it stands, the suffering condition is redundant. It is perhaps for this reason that some defenders of the Joint View hold that the suffering in question must be of a certain, limited sort. Immediately following the passage cited above, Sumner writes that

The common denominator for all these forms of suffering is that they must be the product of some diagnosable medical condition (such as an illness or disability). It is not enough to be simply 'tired of life'; assisted death is a form of medical treatment and, as such, should be reserved for the relief of suffering due to a medical condition (Sumner 2011, 171).

With this further restriction in place, the welfare condition avoids collapsing into the autonomy condition (in the way just mentioned). This restriction is therefore essential to preserving the Joint View. 
It is far from obvious, however, what exactly counts as a "medical condition" in this context. In our view, this restriction generates a dilemma for the defender of the Joint View: either our best understanding of the concept of "medical condition" will be implausibly ad hoc, or else it will be satisfied in cases of PAD whenever the autonomy condition is satisfied. Let us consider these in turn.

First, consider some possible ways of understanding what a medical condition is in this context. Surely it must be more than just whatever the medical community currently recognizes as medical conditions. The obvious problem with this is that it would prevent us from ever expanding the concept to include certain new discoveries in medicine, psychology, and so on. Moreover, it is difficult to see what is so morally important about whatever happen to be currently recognized as medical conditions, such that this designation could form such a crucial part of a moral restriction on PAD. We doubt that such a plainly descriptive or sociological version of the concept could achieve this.

One might hold instead that something is a medical condition if and only if it belongs to some other category - for example, illness or disability - that we tend to view as having moral salience. This seemed to be Sumner's suggestion in the passage quoted above, though he does not put it quite this strongly. In any case, we see here again similar worries concerning arbitrary limitations in scope for these concepts. For example, take the case of life fatigue, which Sumner appears to think does not qualify as an illness (though it is suffering). On what grounds should it be disqualified as an illness (and, therefore, a medical condition)? We have just seen that it won't do to insist that it isn't currently recognized as a medical condition; this approach is a non-starter. Nor could one claim that it is not a medical condition in virtue of the fact that it is not something that the medical profession ought to treat. This would be to beg the very question at issue here. Furthermore, it is surely not a question of the condition's significance to the patient. Life fatigue can be a form of suffering equal to, or perhaps greater in significance and severity, than many other forms of suffering. After all, people already seek PAD on this basis; this should suffice as proof of its significance.

Even if we could find an understanding of the concept of illness such that conditions such as life fatigue are ruled out, it is still far from obvious why the concept of "medical conditions" should be restricted to just illnesses and disabilities. Medical professionals regularly treat patients who do not have illnesses, or in ways that are not related to their illnesses, and we do not insist 
that these treatments are inappropriate simply in virtue of the fact that they treat something other than a "medical condition", narrowly defined. (Consider, for example, cosmetic procedures, athletic treatments, the various kinds of psychological treatments that are not based in illnesses or medical conditions, and-an example to which we will return-non-therapeutic abortion.) Moreover, some of Sumner's own examples - e.g., the "loss of the ability to do what makes life worth living" - are not necessarily the products of any diagnosable medical condition, at least on the sort of definition of this concept defenders of this restriction, like Sumner, seem to endorse (Sumner 2011, 171).

It would therefore be implausibly ad hoc to stipulate that treating something like life fatigue or existential suffering involves treating something that is not a medical condition. But perhaps we can go a different way - one that is more focused on the medical professional's skill set and the needs of the patient. In other words, we can understand a medical condition as, roughly, any condition for which patients seek treatment from a medical professional that requires (in perhaps a rather broad sense) their particular skills and capacities (Boorse 2016, Hesslow 1993). In other words, on this view, a medical condition is essentially whatever the patient seeks the help of her doctor for, provided that her doctor is capable of ameliorating or assisting her. This will of course need to be spelled out more, but the basic idea is clear: it locates the concept at the intersection of what patients look for from their medical professionals, and what those professionals are (essentially) trained to do or capable of doing in virtue of their particular knowledge and skill set. ${ }^{3}$ This definition will still have some of the problems of the sociological account we sketched earlier, and so will require some refinement to avoid those problems.

But the bigger problem, at least for the defender of the Joint View, is that PAD will qualify as a medical condition on this definition essentially whenever the autonomy condition is satisfied. That is, on a suitably robust understanding of what autonomy requires, whatever condition prompts the request for PAD will qualify as a medical condition in virtue of the fact that the patient requests the assistance of a physician in treating it with PAD. In other words, the proposed independent

\footnotetext{
${ }^{3}$ One might worry that this definition begs the question: a medical condition is just whatever relies on medical skills, but these are defined in reference to the conditions they are aiming to treat. But this is not the case. For one thing, as patients seek out doctors for various treatments of whatever sort, doctors might develop new skills - that is, the two concepts might, and probably do, co-evolve. Boorse and Hesslow advocate for revising the way medicine usually identifies itself as a healing profession. Their arguments, and ours, require a change in that perspective.
} 
criterion for eligibility for PAD that concerns medical conditions is unnecessary: this condition simply collapses into the autonomy condition.

The final part of the welfare condition for PAD holds that no other treatment option for the condition is acceptable to the patient (Sumner 2017, 44). But once again, on our best understanding of what this criterion requires, it also collapses into the autonomy condition. After all, an appropriately robust autonomy condition will require that the patient be informed about all relevant alternatives; in other words, autonomy requires informed consent. If her declination of all other alternatives is autonomous, then this should satisfy the proposed criterion. But again, we do not need a separate criterion to achieve this; the autonomy condition alone can accommodate it.

The Oregon Model, according to which the patient must have a terminal illness from which she will die within six months to qualify for assistance in dying, takes a different approach to specifying the welfare condition (Sumner 2017, 91-92). A downside with an explicit suffering condition is that it is purely subjective: there is no way to verify that the patient's suffering really is intolerable. Instead, the physician can only verify that the patient has an incurable illness. Among other worries, this increases the chance of abuse or misapplication. This is one way of justifying the inclusion by Canadian lawmakers of a clause requiring that the patient's death be 'reasonably foreseeable', even though the Supreme Court of Canada didn't specify such a condition when it struck down the prohibition on medical assistance in dying (Sumner 2017, 81-85). In contrast, requiring a terminal illness is an attempt, albeit indirectly, to make suffering objective. ${ }^{4}$ Even though Sumner rejects this sort of move, he grants the objectivity point: "The terminal diagnosis requirement, with its six-month horizon, has the advantage of being more or less objective, based as it is on medical judgment concerning the patient's prognosis" (Sumner 2017, 93). The point of such a condition is that the patient is going to die soon from the illness, so she can be justified in concluding that her remaining time is not worth living. The thought is that a terminal illness is a horrible thing to experience, regardless of the details of the illness, so PAD is reasonable. In contrast, it is harder to conclude that one's life is not worth living when death is further away, and the risk of error grows. Ronald Dworkin et al. describe this view (without endorsing it): “A state

\footnotetext{
${ }^{4}$ There are also pragmatic and legal reasons for a terminal-illness condition. Pragmatically, it might have a better chance of being passed into law (Young 2007, 18). Legally, R.A. Sedler argues that the state's interest in preserving life doesn't apply to those with a terminal illness: "A ban on the use of physician-prescribed medications by a terminally ill person to hasten inevitable death does not advance any conceivable interest in "preserving life"" (Sedler 1993, 24). Because we are focused on the ethical justifications for PAD, we will set aside arguments of this sort.
} 
might assert, for example, that people who are not terminally ill, but who have formed a desire to die, are, as a group, very likely later to be grateful if they are prevented from taking their own lives" (Dworkin et al. 1997). Martin Gunderson and David Mayo give the same argument as one defense of the terminal-illness condition: "there is a much greater likelihood that a nonterminal patient who wishes to die could be restored to a meaningful existence, and hence a much greater chance that physician-assisted death would be a mistake for that patient, than would be the case for a patient near death and for whom the time and the manner of death now loom as the only remaining central questions of their lives" $(2000,22)$. The use of this condition is thus different than the direct appeal to suffering, but still makes use of welfare.

As we described above, if there's going to be a welfare condition, we support a subjective approach. This is because the badness of suffering is itself subjective, and attempts to objectify it through a terminal-illness condition will be both unduly restrictive and broad. Under such a model, patients with intolerable suffering who will live for longer than six months are ineligible for PAD, even though they will suffer more than those who will die sooner. Further, the Oregon Model allows persons with no suffering to legally access PAD, provided that they are terminally ill. While this result aligns with our own view, there is no justification for an arbitrary time frame. Someone who is tired of life might well otherwise die within six months, but there is no ethical justification for temporal restrictions of this sort.

The upshot of this discussion is that the welfare condition, properly understood, is either otiose or implausible. In our view, the autonomy condition accommodates the most important parts of the welfare condition. If this is true, the Joint View, as it stands, is false. One option is to expand the Joint View to accommodate the broader range of justified PAD. Another option is simply to reject the Joint View by way of rejecting the welfare condition. On this view, the autonomy condition alone is sufficient.

\section{An Autonomy-Centered Account}

The foregoing arguments suggest that the Joint View is unsuccessful, and that a better view is one we call Autonomy Only. According to this view, satisfying the autonomy condition is both necessary and sufficient for (morally) justified PAD (of the particular sort of PAD that we are focused on here). Our aim in this section is to explain the commitments of this view and respond to some objections that might seem to show Autonomy Only is implausible. 
Autonomy Only has received philosophical attention, but always as part of an argument against PAD. A well-known example comes from Daniel Callahan, who offers what he takes to be a reductio of it when he says that "If we really believe in self-determination, then any competent person should have a right to be killed by a doctor for any reason that suits him" (Callahan 1992, 54). This is not quite our view. For instance, we are not arguing that patients have a right to be killed. Nevertheless, our view is that the reasons for wanting to die are entirely up to the patient, provided that she has the capacity to make the decision.

In addition to the arguments of the previous section, there are further reasons to prefer Autonomy Only over the Joint View. First, Autonomy Only does not require (as the Joint View does) that physicians and policymakers make judgments about which lives are worth living - that is, by judging that certain illnesses or disabilities can satisfy the welfare condition while others cannot. Some philosophers have pointed out that this sort of judgment has the effect of enshrining attitudes that are ableist and ageist by taking certain disabilities and old age as enabling factors for PAD (Bickenbach 1998). Furthermore, by setting a limit for the kinds of conditions that can satisfy welfare, the Joint View also requires that doctors judge that some reasons for choosing PAD are insufficiently serious, which further imposes on patients a view about which lives are worth living. ${ }^{5}$ By jettisoning the welfare condition, Autonomy Only avoids these worries.

Moreover, as we mentioned earlier, many cases of end-of-life suffering involve others to whom one has special obligations, such as family or friends. Given the prolonged suffering one's condition might impose on others, many patients wish to die so as not to become a burden to others, and some have even argued that there may be a (perhaps merely pro tanto) duty to die (Hardwig 1997). This idea is, of course, contentious; we cannot offer a full treatment of it here. It will suffice, however, to note that, to the extent that this view is plausible, Autonomy Only better captures it than the Joint View. This is because the Joint View cannot easily accommodate cases where the interest in hastening death is not located primarily in the patient's own suffering. By contrast, Autonomy Only can accommodate this preference or duty, provided of course that the decision is truly autonomous and not, as some may worry, the result of undue pressure from others.

\footnotetext{
${ }^{5}$ Callahan asks "Are doctors now to be given the right to make judgments about the kinds of life worth living and to give their blessing to suicide for those they judge wanting? What conceivable competence, technical or moral, could doctors claim to play such a role? Are we to medicalize suicide, turning judgments about its worth and value into one more clinical issue? Yes, those are rhetorical questions" $(1992,55)$. With deference to Callahan, the point of the Autonomy Only model is that it removes the need for physicians to make such judgements. Their gatekeeping role is narrowed to determining capacity.
} 
Finally, consider cases of passive euthanasia where the patient refuses treatment on the basis of her values, such as the denial of life-saving blood transfusions by Jehovah's Witnesses. Many people agree that, if a Jehovah's Witness makes a fully-informed and autonomous decision to deny the transfusion, doctors have no right to insist further, and do no wrong in allowing the patient to die. In other words, we tend to think that the autonomy condition is sufficient in many cases of passive euthanasia. We should ask, then, why the same would not be true in active euthanasia cases, such as the forms of PAD we are considering here. Of course, many think there are important differences between passive and active cases. For one thing, there is an important difference between the negative right of non-interference and the positive right to aid in dying. This may point to relevant differences in what we can require of doctors, among other things. However, this issue is irrelevant when the doctor is willing to perform PAD. Provided the patient's choice is autonomous in both cases, and assuming that the doctor is willing to accede to the patient's autonomous request, it is not clear what difference the distinction between passive and active could make in this case. In short, then, assuming we grant Autonomy Only in cases of passive euthanasia, it is not obvious why it should not also apply in active euthanasia as well.

Despite the many advantages of Autonomy Only, there are a number of objections that are worth considering. One popular objection to Autonomy Only is that it seems to give the wrong verdict in a number of cases. First, consider a case by Jerome Bickenbach: On a view like Autonomy Only, "qualified doctors could patrol school grounds waiting for despondent but mentally competent seventeen-year-olds who, having failed geography or been unable to find a date for the prom, might want to use their assisted-suicide services" (Bickenbach 1998, 130). Bickenbach suggests that granting PAD to the despondent teenager would be impermissible. And at first glance, it seems that Autonomy Only is committed to saying that it would be permissible.

But this example trades on an ambiguity. Though the case stipulates that the teenager is mentally competent, it also emphasizes that he is despondent; it also matters that he is young, which encourages us to view his theoretical desire for PAD as naive or ill-considered. But the fact that he is despondent (in the sense meant in the example) and naive counts strongly against the stipulation that he is mentally competent — or at least, sufficiently mentally competent to make an informed choice about ending his life. It also invites us to read his condition as insufficiently informed of the relevant facts-i.e., of how his current difficulties are overwhelmingly likely to be ephemeral. In other words, on one reading of the case, the despondent teenager simply fails to 
satisfy autonomy. However, if the case is told in such a way that avoids these suggestions-for example, by stipulating that his desire for PAD is stable over time and well informed; that his competency is clear; that doubts about his naivety or hastiness are assuaged - then we are less bothered by the conclusion that granting him access to PAD would be permitted, as Autonomy Only holds. Perhaps it will be difficult to be sure that a young adult in his circumstances could be sufficiently well informed about this question, but if the example is such that we are to stipulate that he is truly autonomous, then we are willing to accept the conclusion.

Another challenge to Autonomy Only concerns someone who requests PAD in order to fulfill certain values that are only achievable upon his death or via his death-for example, to become an organ donor. Some might judge that this patient is not eligible for PAD, since he is not undergoing any kind of suffering whatsoever. And given that there is no suffering, his circumstances cannot be said to be intolerable to him. Thus, the first part of this objection concerns the reductivist approach we have taken in defending Autonomy Only. On our view, the suffering condition is automatically satisfied whenever an individual opts for PAD. But this example seems to show that this is false: there are some cases in which an individual makes an autonomous choice that does not seem to involve any suffering. Furthermore, Autonomy Only gives the wrong verdict in this case: it holds that the patient is eligible for PAD. The Joint View, by contrast, gives the right verdict: the patient is ineligible, since he fails to satisfy welfare.

Let us take these two points in turn. First, as we argued above, it need not be the case that the individual experiences some standard form of suffering. It is enough that she judges her life less valuable than death, where 'valuable' is broader than prudential value. Sometimes this will be the result of a condition we can easily understand, such as the profound loss of dignity or functioning. But sometimes it will involve the loss of other values that are harder for us to understand, such as in the case of someone who autonomously judges his life to be no longer worth living, because it deprives him of the ability to act in accordance with his values (in this case, the value of being able to offer life-saving support to others). Whether or not this aligns with certain pre-theoretical notions of suffering is irrelevant, given that the importance of suffering itself rests on the idea of what makes life worth living.

As for the verdict itself, we must once again get clear about the specifics of the example. It is hard to imagine a case in which a perfectly healthy individual would choose to significantly prematurely end his life in order to become an organ donor. Indeed, given the peculiarity of this 
request, it is not hard to imagine that many doctors would feel incapable of judging with certainty that the patient's request is truly autonomous, and would therefore decline to assist. However, once we grant that the decision really is autonomous, the remaining problem concerns only the condition that gave rise to his decision. But as we have already said, if this decision truly is autonomous, then he judges that the value of death outweighs the value of his continued life. And this is all we need to know.

At this point, one might object to our view by claiming that we are sneaking in the welfare condition via judgments of autonomy. According to this objection, a physician's assessment of a patient's autonomy will necessarily require looking at the range of facts about the patient's condition-for example, their health and other relevant medical information, such as their age, imminent decline, and so forth. And judgments of autonomy will vary according to the relative presence of these indicators. But this, the objection goes, is just the welfare condition by another name: the very same considerations that were relevant to the welfare condition under the Joint View appear again here. Thus, our view does not really reject the welfare condition after all; it merely moves it elsewhere in the analysis.

Of course, we do not deny that physicians' judgments will generally proceed in this way. Certainly many physicians will find it easier to judge a request for PAD as autonomous when the patient is nearing the end of her life, suffers from a recognized medical condition, and so on. But it does not follow from this observation about how autonomy is assessed in practice that there is therefore a welfare condition lurking in the background of our view. There is conceptual distance between the two conditions: the autonomy condition can still be satisfied without requiring anything like the welfare condition. Put differently, while actual judgments of autonomy may often resort to considerations of welfare for support, there is no necessary connection between these two in theory.

To see this more clearly, consider a case in which all of the elements that might facilitate assessments of autonomy are absent: the patient is not at the end of her life, does not suffer from a recognized medical condition, and so on. The Joint View would deny PAD in this case: without fulfillment of the welfare condition, PAD is unjustified. And were it the case that our view had a welfare condition hiding within the autonomy condition, we would judge that the patient is ineligible for PAD, in virtue of the fact that she would not be judged to be autonomous due to the absence of any welfare-based indicators. In other words, in this sort of case, judging the patient to 
be autonomous would be impossible by virtue of the hidden welfare condition. However, properly understood, our view holds that, while it may be more challenging for physicians to assess autonomy in the absence of these typical indicators, this does not preclude the possibility that the patient could be judged to be autonomous and, therefore, eligible for PAD. ${ }^{6}$

If we accept the Autonomy Only view for PAD, does consistency demand that we accept it for all other decisions in healthcare? Not necessarily. Indeed, there seem to us good reasons for rejecting this principle in certain other cases. Imagine a patient who requests a prescription for a non-lethal but still very dangerous drug (e.g., one of the very addictive opioids). Even if this decision is made fully autonomously, we suspect most would judge that the physician is not permitted to accede to this request. It is not clear whether this intuition rests on reasons of welfare, or if there is something particular about prescribing potentially harmful drugs that is unique.

So, it is not the case that our view applies to every healthcare decision; but neither is it the case that Autonomy Only is an ad hoc or sui generis principle, applicable only to cases PAD. To see this, consider two other examples. First, non-therapeutic abortion is usually defended along autonomy-only lines, and correctly so. Judith Thomson's “A Defense of Abortion” (1971) rests on the claim that people have a right to decide what happens to them, a foundational point which is also brought out by the pro-choice phrase "my body, my choice." Those who defend the right to abortion typically place no further conditions on access, besides, perhaps, restricting late-term abortions. In particular, there is no welfare condition. Doctors do not assess whether an abortion is in the woman's best interest, and the woman is not required to defend her decision by showing that it is good for her. Instead, she gets access to the procedure because she wants it, which, in our view, is the right approach. This is true of many other reproduction-based procedures, including vasectomy, tubal ligation, and pharmaceutical birth control.

Second, consider "bodily integrity identity disorder," a condition in which a person perceives a body part such as a limb or organ as foreign to her and wishes to have it removed, even though there is nothing physically wrong with it. On our view, someone's belief that a limb does not belong to her is grounds for an autonomous decision to have it removed, as its attachment is

\footnotetext{
${ }^{6}$ One might worry that we are here abandoning our point about Autonomy Only being less ableist than the Joint View, insofar as Autonomy Only might still create barriers to access for those with less commonly accepted conditions or values. It may be true that in practice Autonomy Only still allows for certain ableist judgments of this sort. But it should be clear enough that Autonomy Only does better on this front than the Joint View, which counts in no small way in its favor.
} 
intolerable to her. If other treatment options were proposed and either failed or were rejected, we see no problem with removing the body part. Note that there's a welfare-based argument for the same conclusion: someone who feels that one of her limbs doesn't belong to her experiences extreme suffering. On this view, the question isn't whether the limb is healthy, but the impact its presence makes on the agent's welfare. While some will surely disagree with the conclusion provided by Autonomy Only, we are not troubled by it. Nor are we alone in this judgment: other philosophers have also argued that autonomy is central condition for justifiably acceding to such requests (Bayne and Levy 2005).

These two examples suggest that some types of medical treatment should be granted just because the patient has autonomously requested it. But this doesn't mean that all healthcare decisions fall under the banner of 'my body, my choice'. While we will not attempt to answer the question of how far the scope of 'my body, my choice' extends, we will simply note there is nothing fundamentally inconsistent about us claiming that PAD should be Autonomy Only while opioid access shouldn't be. Those who think there is an inconsistency will either have to reject Autonomy Only for abortion, which might be unwelcome, or accept Autonomy Only for opioids, which they might also view as a mistake. Although the scope of Autonomy Only is unclear, abortion and PAD have similarities. Most importantly, they both involve significant decisions about how our lives go. Perhaps there are additional procedures that should be included-indeed we think that other procedures should be included - but that delineation goes beyond our narrow goal here.

A different set of problems concerns making Autonomy Only into law. Though we have no specific recommendations for policy details, such as the appropriate waiting period between requests, there is a more general worry that physicians are unable to assess competency for requests that are not based in standard suffering. This objection is unsuccessful for three reasons. First, physicians are already tasked with making competency assessments that go beyond the scope of medicine (e.g., they affect control over finances), and these include ensuring that the patient isn't being coerced. If physicians can already assess for coercion, there is no reason to think they will be unable to in autonomy-only cases. Second, some worry that judging an autonomy-only PAD request means physicians must assess what are ultimately subjective values. But this is no different from present PAD laws, including Canada's, which has as a condition that the patient finds her suffering intolerable. Such judgements are necessarily, and appropriately, subjective. Third, while 
we think there is no reason to exclude physicians from assessing for autonomy-only PAD, it's possible that the best policy will put the task of assessing requests on others, such as judges.

Additional practical concerns might arise from broader medical and societal factors, such as how healthcare is funded. For example, on our view, someone could qualify for PAD because she was unwilling to pay for her healthcare expenses. We accept this implication. Someone might value her ability to support others, such as her family, and desire not to be a burden more than she values her remaining time alive. Paying for her own medical bills by remaining alive would be intolerable to her, and so she could autonomously choose to die. Of course, these decisions are sometimes a result of unjust social circumstances, such as barriers to access and unjust poverty. We ought to be cautious about how we understand autonomy in such contexts: while we agree that social injustices can limit one's autonomy in significant ways, we are also uncomfortable with the conclusion that such people would be denied relief from what they take to be an intolerable life for them. We do not aim to settle this question here. Suffice it to say that our view can accommodate a range of possibilities with respect to this issue.

A different practical issue is the broad category of conscientious objection. Given that some cases of PAD might involve patients who do not present any of the standard symptoms of intolerable suffering, many healthcare providers might believe themselves incapable of judging whether autonomy is satisfied. More generally, many healthcare providers might be unwilling to perform PAD in autonomy-only cases for other principled reasons. For example, some physicians might find acceding to autonomous requests for assistance in dying in certain cases to be too significant a departure from the physician's own understanding of her professional role. Our view makes no policy recommendation on whether they should be permitted to conscientiously object or not. Our minimal claim is that PAD is permissible in cases in which a patient makes an autonomous request and a physician is willing to accede to that request.

Some may press this point further and insist that granting requests in such cases is not simply a matter of violating individual conscience, but rather constitutes a violation of an objective professional code that is binding on all physicians. To treat this point fully would require settling big questions such as what the goals of medicine are, whether role morality is the right approach to thinking of physicians' obligations, and if so, what the physician's particular role obligations are. We are unable to give proper attention to these issues here. It will suffice only to register our skepticism that role morality offers the best system for thinking about physicians' permissions. 
And even if it were the right approach, we doubt that it would be so clearly settled against the view we have outlined here. The question of what a physician's role consists in is an open one, and it is far from decisive against our argument to cite one possible conception of that role, when certain others are perfectly consistent with it.

While we have considered several of the many practical objections to our view, it is worth stressing that our focus in this paper has been on defending Autonomy Only on its ethical merits. It might still be the case that unintended consequences are sufficiently likely to justify restricting PAD policy more than Autonomy Only specifies. Assessing the practicality or legal feasibility of our view is a task for a different paper.

\section{Conclusion}

In this essay, we have argued that the Joint View is false, as its welfare condition is either implausible or otiose. We have sketched the basics of an Autonomy Only view, according to which an autonomous request for PAD is sufficient for its moral permissibility. To be sure, a full defense of such a view would require a more detailed treatment. In particular, we have said nothing about the law or policy implications of our view. Our goal here has been only to show that such a view is ethically plausible, consistent, and deserving of more serious attention.

Although our view allows for a broader range of PAD cases than the Joint View, were ours made into law, the majority of cases would still meet the current legal criteria of places such as Canada. But we have also argued that autonomy on its own is sufficient in many cases, such as being tired of life or wanting to avoid burdening others. Our argument therefore supports Ronald Dworkin's famous claim that "making someone die in a way that others approve, but he believes a horrifying contradiction of his life, is a devastating, odious form of tyranny" (Dworkin 1994, 217).

\section{Acknowledgements}

[redacted for blind review]

\section{References}

Aviv, R. 2015. The death treatment: when should people with a non-terminal illness be helped to die? The New Yorker. June 15. 
Barutta, J. and J. Vollmann. 2015. Physician-assisted death with limited access to palliative care. Journal of Medical Ethics 41(8): 652.

Bayne, T. and N. Levy. 2005. Amputees by choice: body integrity identity disorder and the ethics of amputation. Journal of Applied Philosophy 22(1): 75-86.

Beauchamp, T. and J. Childress. 2012. Principles of Biomedical Ethics, 7th ed. New York: Oxford University Press.

Bickenbach, J. 1998. Disability and life-ending decisions. In Physician-assisted suicide: expanding the debate, edited by M. Battin, R. Rhodes, and A. Silvers, 123-132. New York: Routledge.

Boorse, C. 2016. Goals of medicine. In Naturalism in the philosophy of health: issues and implications, edited by E. Giroux, 145-177. New York: Springer.

Buchanan, A., and D. Brock. 1990. Deciding for others. Cambridge: Cambridge University Press.

De Haan, J. 2002. The ethics of euthanasia: advocates' perspectives. Bioethics 16: 154-172.

Donchin, A. 2000. Autonomy, interdependence, and assisted suicide: respecting boundaries/crossing lines. Bioethics 14(3): 187-204.

Downie, J. and S. Sherwin. 1996. Feminist exploration of issues around assisted death. Saint Louis University Public Law Review 15(2): 303-330.

Dworkin, R. 1994. Life's dominion. New York: Random House, New York.

Dworkin, R., T. Nagel, R. Nozick, J. Rawls, T. Scanlon, and J. Thomson. 1997. Assisted suicide: The philosophers' brief. The New York Review of Books. March 27: 41-47.

Fletcher, G. 2016. The philosophy of well-being: an introduction. New York: Routledge.

Ganzini, L. 2004. The Oregon Experience. In Physician-Assisted Dying: The Case for Palliative Care and Patient Choice, edited b y T. Quill and M. Battin. Baltimore: Johns Hopkins University Press.

Grant, K. 2018. Medically assisted death allows couple married almost 73 years to die together. The Globe and Mail, April 18.

Gunderson, M., and D. Mayo. 2000. Restricting physician-assisted death to the terminally ill. Hastings Center Report 30(6): 17-23.

Hardwig, J. 1997. Is there a duty to die? Hastings Center Report 27: 34-42.

Hesslow, G. 1993. Do we need a concept of disease? Theoretical Medicine 14: 1-14.

Ho, A. 2008. Relational autonomy or undue pressure?: Family's role in medical decisionmaking. Scandinavian Journal of Caring Sciences 22(1): 128-135.

Huxtable, R., and M. Moller 2007. Setting a principled boundary? euthanasia as a response to life fatigue. Bioethics 21:117-126.

Jennings, B. 2016. Reconceptualizing autonomy: a relational turn in bioethics. Hastings Center Report 46(3): 11-16.

Kagan, S. 2014. An introduction to ill-being. In Oxford Studies in Normative Ethics, volume 4, edited by M. Timmons. Oxford: Oxford University Press.

Kymlicka, W. 1989. Liberalism, community, and culture. Oxford: Oxford University Press.

Li M., et al. 2017. Medical assistance in dying_-implementing a hospital-based program in canada. New England Journal of Medicine 376:2082-2088.

Mackenzie, C. and N. Stoljar. 2000. "Introduction: autonomy refigured." In Relational autonomy: feminist perspectives on autonomy, agency, and the social self, edited by Catriona Mackenzie and Natalie Stoljar, 3-34. New York: Oxford University Press. 
Marquet, R.L., et al. 2003. Twenty Five Years of Requests for Euthanasia and Physician Assisted Suicide in Dutch General Practice: Trend Analysis. British Medical Journal 327:7408.

Maynard, B. 2014. My right to death with dignity at 29. CNN.com. November 2.

McLeod, C. and S. Sherwin. 2000. "Relational autonomy, self-trust, and health care for patients who are oppressed." In Relational autonomy: feminist perspectives on autonomy, agency, and the social self, edited by Catriona Mackenzie and Natalie Stoljar, 259-279. New York: Oxford University Press.

Mill, J. 1859. On liberty. New York: Norton.

Miller, F. 2016. Should a legal option of physician-assisted death include those who are "tired of life"?. Perspectives on Biology and Medicine 59: 351-363.

Pearlman, R. and H. Starks. 2004. Why do people seek physician-assisted death? In PhysicianAssisted Dying: The Case for Palliative Care and Patient Choice, edited by T. Quill and M. Battin. Baltimore: Johns Hopkins University Press.

Sedler, R.A. 1993. The constitution and hastening inevitable death. Hastings Center Report 23(5): 20-25.

Steinbrook, R. 2008. Physician-assisted death-from Oregon to Washington state. New England Journal of Medicine 359: 2513-2515.

Sumner, L.W. 1996. Welfare, happiness, and ethics. Oxford: Oxford University Press.

Sumner, L.W. 2011. Assisted death. New York: Oxford University Press.

Sumner, L.W. 2017. Physician-assisted death: What everyone needs to know. New York: Oxford University Press.

Thomson, J. 1971. A defense of abortion. Philosophy and Public Affairs 1(1): 47-66.

Wall, S. 1998. Liberalism, perfection and restraint. Cambridge: Cambridge University Press.

Young, R. 2007. Medically assisted death. Cambridge: Cambridge University Press. 